\title{
O Estado Democrático de Direito Ambiental e as catástrofes ambientais: evolução histórica e desafios
}

\author{
The Democratic State of Environmental Law and \\ environmental catastrophes: historical evolution and \\ challenges
}

\author{
Fernanda Dalla Libera Damacena* \\ Délton Winter de Carvalho**
}

\section{Resumo}

O presente artigo apresenta a evolução e consolidação histórica do Estado de Direito Ambiental, e, sobretudo, suas novas missões e desafios. Dentre os novos enfrentamentos, riscos e responsabilidades a serem geridos pelo Estado e pelo direito, estão as catástrofes ambientais. Tendo essa temática como pano de fundo, o artigo explorará, em um primeiro momento, a evolução do Estado de Direito e suas características ao longo do tempo. Na sequência, serão apresentadas as intersecções do Estado de Direito Ambiental e as catástrofes ambientais. Por fim, buscará se colocar de que forma vem se estruturando o modelo legislativo destas no Brasil.

Palavras-chave: Estado. Direito. Ambiental. Catástrofes. Estrutura.

\section{Abstract}

This article presents the historical evolution and consolidation of the State Environmental Law, and especially its new tasks and challenges. Among the new engagements, responsibilities and risks to be managed by the state and law are environmental disasters. Having this theme as a backdrop, the article

Especialista e mestre em Direito Público. Professora e coordenadora da Especialização em Direito Ambiental UNISINOS. Advogada. São Leopoldo - RS - Brasil. E-mail: fdamacena@ unisinos.br

* Doutor em Direito UNISINOS. Mestre em Direito Público UNISINOS. Advogado e consultor jurídico. Professor PPGD Unisinos. São Leopoldo - RS - Brasil. E-mail: deltonwc@via-rs.net 
will explore, at first, the evolution of the rule of law and their characteristics over time. Following are shown the intersections of State for Environmental Law and Environmental Catastrophes. Finally, we seek to put in what way has been structuring the legislative model of disasters in Brazil.

Keywords: State. Law. Environmental. Catastrophes. Structure.

\section{Introdução}

A recorrência de catástrofes ${ }^{1}$ no Brasil tem se tornado cada vez maior. Segundo dados coletados pelo EM-DAT (2010), entre os anos de 1980-2010, foram registrados no país 146 desastres, com 4.948 pessoas mortas (estimativa de 160 mortes por ano), 47.984 .677 pessoas afetadas (média de afetados/ano $=1.547 .893$ ) e um prejuízo econômico de 9.226 .170 dólares. Tais números demonstram que o enfrentamento das catástrofes ambientais e a gestão integrada dos riscos a elas correspondentes requerem prioridade máxima nas agendas executiva, legislativa e judicial (VERCHICK, 2010).

É num cenário de necessária reação a uma quantidade enorme de consequências radicais, em boa parte, fruto de sua atuação, que a sociedade, o Estado e os sistemas sociais se deparam e enfrentam as ressonâncias oriundas das catástrofes. Cada vez mais comuns e com graus de magnitude preocupantes, os desastres ambientais (naturais, industriais ou híbridos) surgem como estímulos que causam um processo de autoirritabilidade no direito, na política, na economia e em outros sistemas sociais. Diante dessa realidade, um dos maiores desafios dos sistemas é racionalizá-la a partir de uma organização e estrutura próprias.

O presente artigo apresenta a evolução e consolidação históricas do Estado de Direito Ambiental, sobretudo suas novas missões e

\footnotetext{
1 Os termos "desastre" e "catástrofe" são considerados sinônimos.
} 
desafios. Por Estado de Direito Ambiental, compreende-se as alterações estruturais havidas no Estado e no direito para reagir aos riscos ecológicos produzidos e distribuídos pela sociedade pós-industrial. Dentre os novos desafios, riscos e responsabilidades a serem geridos pelo Estado e pelo direito, estão as catástrofes ambientais. Diante dessa perspectiva, em um primeiro momento, o artigo explorará a configuração do Estado Democrático de Direito e sua consolidação histórica. Posteriormente, serão avaliadas as relações e intersecções entre o Estado de Direito Ambiental e as catástrofes ambientais. Por fim, busca-se se demonstrar de que forma vem se estruturando o modelo legislativo dos desastres no Brasil.

\section{Configuração do Estado Democrático Ambiental e sua consolidação histórica}

Os Estados constitucionais ocidentais consistem na integração entre a política e o direito, sendo estes organizações que, de forma local e territorializada, estruturam tradicionalmente a complexidade social, global e pluralista. Ao longo dos últimos séculos, o desenvolvimento técnico-científico foi colocado à disposição da economia, que, por sua vez, intensificou a utilização deste nas cadeias produtivas industriais, gerando um possível comprometimento das condições ambientais e do equilíbrio ecológico do entorno. Enquanto o direito produziu uma comunicação ecológica em seu âmbito (comunicação jurídica), a partir da institucionalização do direito ambiental, a política encontra-se fundada num fenômeno de ecodemocratização ${ }^{2}$. O ponto de contato entre o direito e a política ambiental se dá a partir da noção de Estado Democrático Ambiental, cujo sentido consiste na absorção da função

Denominamos de "ecodemocratização" o processo de sensibilização das formas democráticas às necessidades impostas pela questão ambiental, devendo estimular a participação direta dos cidadãos (audiências públicas em processos de licenciamento ambiental) nos processos de tomada de decisão que possam comprometer os interesses das futuras gerações ou que façam uso de recursos naturais. 
de proteção ambiental como tarefa e objetivo do Estado, enquanto organização integrante do sistema político.

O direito, na modernidade, encontrava-se diretamente vinculado a uma noção forte de centralidade do Estado nacional, detendo uma racionalidade jurídica formada sob a égide do normativismo ${ }^{3}$. A evolução histórica, contudo, impõe diversas alterações ao posicionamento do Estado no sistema político global (CANOTILHO, 2006). Dessa forma, é fundamental lançarmos nossas observações sobre a evolução histórica do sistema político ocidental, tendo o Estado a função de atuar como organização capaz de efetuar a integração entre direito e política. Assim, o Estado de Direito passa a ser, simultaneamente, uma instituição política (produtora de raison política) e jurídica (validade jurídica) (LUHMANN, 2002, p. 481). Apesar da diferenciação funcional entre direito e política, esse processo de integração exercido pelo Estado é sentido na democratização da política, que, por seu turno, passa a exigir maior proteção e positivação jurídica, sob orientação dos direitos constitucionais (LUHMANN, 2002, p. 483).

Após as revoluções liberais e a consequente institucionalização dos direitos individuais, surge o Estado de Direito de orientação liberal, com a formação de garantias ao cidadão em relação ao (abuso de) poder do Estado. O êxito da burguesia e de suas fundações filosóficas acarretou na constitucionalização dos direitos do indivíduo contra o Estado, impondo obrigações de abstenção e limites à intervenção estatal na vida privada do cidadão. Esses direitos civis e políticos têm como exemplos os direitos à liberdade, igualdade, propriedade, privacidade, entre outros direitos individuais de conteúdo negativo. O Estado liberal consiste numa organização capaz de proporcionar a integração entre o direito e a política, cujo átomo das concepções e construções filosóficas era o indivíduo.

Como exemplo do Normativismo: Kelsen (2000). No mesmo sentido: Rocha (2003, p. 185); David (2002, p. 70-71). 
Tais direitos fundamentais apresentam um conteúdo abstencionista, cuja garantia depende apenas de um não agir por parte do Estado para a sua concretização. Os direitos fundamentais apresentam-se como um medium integrador do sistema político e do sistema jurídico. A relação Estado/direito, que marca a modernidade, enseja a vinculação dessa geração de direitos com a caracterização do Estado de Direito, segundo o qual o cidadão tem assegurado, pelo Direito, a imposição de limites para a intervenção estatal na esfera privada.

Já a formação do Estado Social ou de Bem-Estar Social decorre do surgimento e constitucionalização dos direitos de segunda geração, impondo obrigações prestacionais ao Estado. A segunda geração de direitos fundamentais surge em resposta ao processo de industrialização proveniente das revoluções industriais e seus efeitos colaterais, a partir da constatação dos desequilíbrios materiais existentes entre grupos sociais; da massificação das relações sociais; da necessidade de incrementação dos níveis de qualidade de vida e inclusão social por meio de prestações políticas e da positivação direitos subjetivos prestacionais; da formação de uma primeira geração de problemas de natureza jurídico-ambiental, como efeitos colaterais dos processos de uma primeira industrialização.

A ampliação dos poderes do Estado, justificados através dos direitos fundamentais positivos, dá azo ao caráter prestacional do ente estatal, demonstrando uma postura intervencionista. Tratando-se o Estado de Bem-Estar Social de uma evolução do Estado de Direito, este exerce seu caráter intervencionista por meio do direito e do dinheiro (LUHMANN, 1997, p. 103-109), mantendo, contudo, as garantias individuais conquistadas na sedimentação de uma primeira geração de direitos fundamentais. Esses direitos sociais têm por característica a intenção de garantir uma igualdade substancial a determinados grupos sociais, através de prestações positivas por parte do Estado na forma jurídica de direitos subjetivos.

O Estado de Bem-Estar Social ou Welfare State efetua uma interface entre programas políticos e direitos subjetivos (DE GIORGI, 1993, p. 108-109), ou seja, entre política e direito, como instrumentos 
de transformação e equilíbrio social. Por sua estrutura prestacional ou positiva, os direitos humanos de segunda geração (saúde, educação, trabalho, habitação, seguridade social etc.) dependem das condições estruturais e econômicas dos Estados, ao contrário dos direitos de primeira geração, que dependem tão somente da abstenção do Estado para a sua garantia. Conforme Bobbio (1992, p. 72):

Enquanto os direitos de liberdade nascem contra o superpoder do Estado - e, portanto, com o objetivo de limitar o poder -, os direitos sociais exigem, para sua realização prática, ou seja, para a passagem da declaração puramente verbal à sua proteção efetiva, precisando o contrário, isto é, a ampliação dos poderes do Estado.

Nessa geração de direitos fundamentais, os titulares dos direitos são sujeitos coletivos. Assim, no plano jurídico-dogmático, assiste-se a uma inversão do objeto do direito subjetivo: enquanto os clássicos direitos individuais reconduziam-se a uma pretensão de omissão dos poderes públicos perante a esfera jurídica privada, os direitos a prestações postulam uma proibição de omissão, impondo ao Estado uma postura ativa a partir de prestações (CANOTILHO, 2004, p. 52).

Como se sabe, os direitos de terceira geração são fruto da democratização na sociedade contemporânea, a qual, através da maior participação dos movimentos populares, acompanha o surgimento do Estado Democrático de Direito. Nesta forma estatal, tem-se uma perspectiva democrática de gestão pública que, no entanto, não exclui as dimensões protegidas pelo Estado de Direito e pelo Estado Social. No Estado Democrático de Direito, há a integração democrática e social entre as três formas estatais e suas gerações de direitos fundamentais (liberal, social e democrático). Eis o seu cerne: a legitimação constitucional dos atos administrativos a partir dos direitos fundamentais.

Com a estrutura política democrática do Estado, os direitos e as expectativas proliferaram-se, uma vez que os novos atores sociais começaram a reivindicar as prestações e a tutela de seus interesses (meio ambiente, consumidores etc.). Esses direitos de terceira geração 
apresentam a expansão da titularidade individual aos grupos, minorias étnicas, religiosas e à humanidade, isto é, sua marca consiste na sua transindividualidade.

No entanto, enquanto os direitos coletivos (stricto sensu) surgidos no Estado Social são marcados pela necessária determinação dos titulares do direito (aposentados, trabalhadores de determinada empresa etc.), os titulares dos interesses tutelados nessa terceira geração dos direitos fundamentais são indeterminados (consumidores atingidos; vítimas de danos ambientais, riscos e desastres ambientais; atingidos por guerras etc).. Ao passo que os direitos coletivos (stricto sensu) decorrem de relações jurídicas de base (pensionistas, vínculos trabalhistas, participação de categorias e classes profissionais), os direitos transindividuais decorrem de situações fáticas (tais como danos ambientais ou a consumidores).

Característicos da sociedade de massas, esses direitos distinguem-se pelo caráter de solidariedade e transindividualidade (interesses coletivos stricto sensu e difusos), pois seu escopo protetivo consiste na garantia de interesses que atingem o gênero humano como um todo (inclusive as futuras gerações). Dentro dessa geração, encontram-se os direitos ao desenvolvimento, à paz, ao patrimônio comum da humanidade e, destacadamente, ao meio ambiente, entre outros interesses cuja titularidade se encontra em uma universalidade de sujeitos indeterminados ou indetermináveis (titularidade difusa).

A consolidação de tais interesses transindividuais, especialmente os interesses difusos, demonstra-se como uma ressonância jurídica à sociedade de risco (BECK, 1992) e ao "efeito bumerangue" dos riscos de natureza pós-industrial, os quais se caracterizam pela capacidade de atingir inclusive aqueles que os produziram e se beneficiaram desse processo (BECK, 1992, p. 37-38). Em outras tintas, tais riscos e danos mostram-se ilimitados, seja em relação às classes sociais, ao território ou mesmo ao tempo.

Apesar de não estar inserido topograficamente no capítulo dos direitos e deveres individuais e coletivos da Constituição brasileira (ou 
seja, fora do Título II - Dos Direitos e Garantias Fundamentais - Capítulo I - Dos Direitos Individuais e Coletivos, da Constituição Federal), não se contesta o conteúdo de direito fundamental à tutela ambiental. A proteção do meio ambiente se manifesta, na dogmática jurídica contemporânea, como um direito fundamental de terceira geração (LEITE; FERREIRA, 2010, p. 7-10), uma vez que se trata de um corolário do próprio direito à vida.

A previsão constitucional do direito ao meio ambiente ecologicamente equilibrado como direito fundamental, de natureza difusa, denota uma dimensão negativa e outra positiva, pois "de um lado, exige que o Estado, por si mesmo, respeite a qualidade do meio ambiente e, de outro lado, requer que o Poder Público seja um garantidor da incolumidade do bem jurídico, ou seja, a qualidade do meio ambiente em função da qualidade de vida" (SILVA, 2002, p. 52).

Com a constitucionalização do direito das presentes e futuras gerações a um meio ambiente ecologicamente equilibrado, tem-se a absorção da função ecológica do Estado Democrático de Direito. Assim, pode ser dito que a inserção da proteção ambiental como objetivo fundamental do Estado repercute no surgimento da "hipótese do Estado de Direito Ambiental", cuja finalidade consiste na defesa do ambiente e na promoção da qualidade de vida (RANGEL, 1994, p. 33).

Nesse fio condutor, Rangel (1994, p. 19-20) descreve o Estado de Direito Ambiental sob um critério estrutural-funcional. No que diz respeito à estrutura do Estado nas relações entre este e a sociedade, surge um Estado que ultrapassa o modelo intervencionista de inspiração keynesiana, promovendo uma postura de transação-negociação direta com os singulares cidadãos e demais pessoas jurídicas. Há um estímulo à participação cidadã através de órgãos com ou sem capacidade organizativa e reivindicativa. Para o mesmo autor, no que diz respeito ao ponto de vista funcional, o Estado assume novas tarefas, tais como a defesa do meio ambiente e a promoção da qualidade de vida. A absorção dessas tarefas pelo Estado consiste em fins qualitativa e substancialmente diversos dos anteriores (Estado de Direito e Estado Social), sendo, muitas vezes, inclusive, conflitantes com estes. 
O Estado Democrático Ambiental ${ }^{4}$ e o próprio direito ambiental consistem em alterações estruturais havidas no Estado e no direito para reagir aos riscos ecológicos produzidos e distribuídos pela sociedade pós-industrial. Na verdade, pode-se concluir que o Estado Democrático Ambiental consiste num processo de ecologização das estruturas do sistema político, em "acoplamento" $\mathrm{com}$ a dinâmica de sensibilização do direito às irritações ecológicas (na ecologização do direito). Contemporaneamente, pode-se dizer, ainda, que os "sistemas parciais procuram nas tecnologias clássicas do Estado de Direito Constitucional uma última 'resposta' ou 'reflexão' para os conflitos de racionalidades" (CANOTILHO, 2004).

Portanto, a partir da constitucionalização da matéria ambiental (art. 225, CF), o Estado (Democrático Ambiental) tem a função de integração estrutural dos vários discursos existentes na sociedade (direito, economia e política), sob uma sensibilização ecológica e a partir da perspectiva moral dos direitos fundamentais como "superdiscurso social" (CANOTILHO, 2004, p. 132).

Assim, após a constitucionalização da matéria ambiental no artigo 225 da Constituição Federal de 1988, agrega-se às funções liberais e sociais do Estado um novo objetivo: a proteção do meio ambiente e da qualidade de vida. Com isso, o Estado Democrático Ambiental trata-se de um Estado que leva o meio ambiente como um critério de aferição para tomar suas decisões. "Além de ser e dever ser um Estado de Direito Democrático e Social, deve ser também um Estado regido por princípios ecológicos" (CANOTILHO, 2003, pp. 101-110). Da mesma forma, este deve apontar para novas formas de participação política, numa verdadeira "democracia sustentada", cujo sentido consiste na forma de democracia adequada ao desenvolvimento ambientalmente justo e durador

\footnotetext{
4 O Estado Ambiental, na doutrina internacional, vem sendo objeto dos trabalhos de autores tais como Michael Kloepfer (Umweltrecht) e José Joaquim Gomes Canotilho (Estado Democrático Ambiental). Na doutrina brasileira, acompanha-os Leite; Ferreira (2004).

5 Fazemos uso da noção de "acoplamento (estrutural)" sob influência de Luhmann (1991); Romesín; García (2001); Romesín; García (1997).
} 
O ideal de sustentabilidade é um ponto que não passa em branco nessa formação de valores e tutela de direitos do Estado Democrático de Direito Ambiental. Especialmente no que concerne ao enfrentamento de novos riscos, como é o caso dos desastres ambientais, "a sustentabilidade importa em transformação social, sendo conceito integrador e unificante, que implica a celebração da unidade homem/natureza, na origem e no destino comum", o que pressupõe, na concepção de Cruz e Bodnar (2011, p. 81), um novo paradigma indutor do direito e da política. Como bem colocam os autores (2011, p. 81-82), "um dos objetivos mais importantes de qualquer futuro com sustentabilidade é a busca constante pelas melhorias sociais das populações mais fragilizadas socialmente", afinal, os problemas sociais e ambientais estão geralmente relacionados. Com os desastres ambientais, não é diferente, pois a potencialização desses típicos problemas ambientais de terceira geração se dá em boa medida pela vulnerabilidade social de algumas localidades que não possuem a mínima condição de preparar-se, enfrentar ou reagir, com mínimas condições de sucesso, a um desastre.

Essa exposição a riscos tão radicais tem razão de ser. Em verdade, a presença do homem sobre a terra pressupõe uma inevitável interação com a natureza. Em relação direta com sua capacidade e número de indivíduos, todas as espécies tendem a alterar o ambiente para satisfazer suas necessidades básicas. A singularidade do homem, nesse aspecto, é a habilidade prodigiosa, física e intelectual, de gerar novas necessidades que vão muito além daquelas decorrentes da subsistência, e a possibilidade de compreender que essa intervenção pode ser contraproducente, tornando-se cada vez mais hostil (FERRER, 2002 , p. 1-3). No caso dos desastres ambientais, a racionalidade humana precisa reconhecer que alguns locais são naturalmente desenhados ("dados"), possuindo uma função ecológica estrutural, vital e sistêmica, logo, sua transformação (ingerência humana) altera o fluxo natural da vida e causa desequilíbrios ecossistêmicos, sociais e econômicos. Essa visão está intimamente relacionada a aspectos como a informação e a participação.

Nesse contexto, destaca-se a abertura do Estado aos problemas ambientais, a partir de uma cooperação e participação mais protagonista 
e ativa dos cidadãos no cumprimento e na elaboração de normas ambientais, consistindo uma base de legitimação para uma "democracia de ambiente" (CANOTILHO, 1995, p. 75). Dessa forma, o direito ambiental impõe uma alteração no pilar democrático do Estado: há uma verdadeira superação da democracia representativa em prol de formas de participação direta dos cidadãos (por exemplo, através das audiências públicas em processos de licenciamento ambientais). O fortalecimento da democracia direta ou participativa em processos de tomada de decisão que repercutem ou possam repercutir na perda da qualidade ambiental tem por justificativa o fato de que as consequências das decisões tomadas acerca das questões ambientais não se prolongam apenas pelos períodos em que os representantes ocupam seus cargos políticos, mas por anos e gerações à frente.

Não resta dúvida de que, diante desse contexto, a realização do Estado Democrático Ambiental não pode se dar alheia a uma obrigatória conciliação dos direitos fundamentais em matéria de ambiente com as demais posições jurídicas subjetivas constitucionalmente fundadas, quer se trate de direitos de primeira geração (tais como a liberdade e a propriedade) ou segunda geração (direitos econômicos e sociais). Estarse-á sempre diante de "fenômenos de colisão de direitos", somente podendo ser objeto de resolvidos a partir da "ponderação de todos os valores constitucionais aplicáveis” (VASCO, 2000, p. 17-18).

Em síntese, pode ser constatado que o Estado Democrático Ambiental consolida-se como uma dimensão do próprio Estado Democrático de Direito, agregando às funções clássicas de garantização de direitos individuais (Estado de Direito) e sociais (Estado Social) a função ambiental, sob o resguardo democrático de legitimação e concretização dos direitos fundamentais (Estado Democrático de Direito). A fim de descrever a necessária pré-compreensão dos operadores jurídicos no Estado Democrático Ambiental, pode-se dizer que, assim como a justiça social é a finalidade do Estado Democrático de Direito, a justiça ambiental é a tarefa e o fim a ser garantido pelo Estado Democrático Ambiental em relação às presentes e futuras gerações. Assim, a formação de um Estado Ambiental é decorrente da inserção de valores ecológicos pelo 
Estado de Direito, havendo uma proposição constitucional para que as futuras ações e decisões sejam limitadas e determinadas por tais valorações, constitucionalmente assumidas (CAMERON, 1999, p. 243).

Contemporaneamente, um dos pontos de grande destaque em termos de justiça/injustiça ambiental, relacionado com as presentes e futuras gerações, pode ser observado a partir dos fatores potencializadores e das consequências das catástrofes ambientais, seja em âmbito local, nacional ou internacional. Frente a essa realidade, o Estado Democrático de Direito possui algumas funções essenciais à persecução de um nível adequado de proteção do meio ambiente. Dentre elas, destaca-se: "o favorecimento da institucionalização de mecanismos mais compatíveis com a natureza diferenciada dos problemas ambientais, priorizando a gestão de riscos que possam comprometer significativamente a qualidade do ambiente" (LEITE; FERREIRA, 2010, p. 17) e a coletividade, além da garantia de proibição do retrocesso ${ }^{6}$. As catástrofes ambientais, pelas características que apresentam (profunda multidisciplinaridade, complexidade, incerteza, improbabilidade e grande magnitude), passam a exigir do direito e da política (Estado Democrático de Direito) maior abstração e assimilação da gestão dos riscos em todas as suas fases, desde a prevenção até a recuperação.

\section{Estado de Direito Ambiental e as catástrofes}

De acordo com dados atuais do International Disaster Data Base (2011), somente no ano de 2010, ocorreram 373 catástrofes "naturais" no Brasil, as quais resultaram em 296.800 mortes, 207 milhões de afetados e 109 bilhões de dólares em prejuízos econômicos.

Sobre o princípio do não retrocesso no Direito Ambiental, recomenda-se a profunda reflexão do prof. Michel Prieur. Revista Novos Estudos Jurídicos, v. 17 - n. 1 - p. 06-17, jan-abr 2012. 
Números dessa ordem são suficientes para a fundamentação de que o tratamento preventivo, de mitigação e recuperação das catástrofes, deve ser um dos principais braços de atuação positiva do Estado de Direito Ambiental. Significa dizer que a gestão de tais situações passa a fazer parte da pauta obrigatória da agenda governamental mundial. Nessa linha, o Estado de Direito Ambiental deve levar em consideração a gestão dos riscos ambientais catastróficos e sua atuação passa a ter como funções cruciais: a prevenção, a mitigação e, no caso de falha destas últimas, planejamento eficiente de estratégias para atuação de emergência, recuperação, reconstrução, redução das vulnerabilidades e implementação da capacidade de resiliência. Para atingir tais objetivos, a atuação estatal precisa, mais do que nunca, ser integrada, organizada, planejada, preventiva e precavida. A antecipação a esse tipo de evento requer a compreensão do risco, como a possibilidade da criação de vínculos com o futuro, através do binômio probabilidade/magnitude, o que deve ser levado em consideração quando da tomada de decisões jurídicas e governamentais.

Se as catástrofes ambientais devem passar a legitimar e operacionalizar tanto as decisões jurídicas ambientais quanto $\mathrm{s}$ atividades de governo, a questão que se impõe é como fazê-lo ou como estruturar essa proposição.

A configuração do Estado Democrático Ambiental consiste no exercício da função ambiental pelo Estado de Direito, sob uma orientação oferecida e ditada pelos parâmetros constitucionais, conformando a atuação estatal e as decisões jurídicas. Significa dizer que tanto as decisões de governo quanto de justiça ambiental relativas às catástrofes deverão respeitar e ter como norte os parâmetros constitucionais e infraconstitucionais estabelecidos.

Além disso, o enquadramento bem sucedido da gestão governamental e jurídica ambiental das catástrofes depende da conectividade e da integração entre as esferas (sistemas) política (legislativa/executiva) e judicial. Catástrofes, em geral, são acontecimentos sistêmicos, multicausais, interconectados e, por essa 
razão, não podem ser enfrentados com sucesso por um sistema isoladamente.

O aspecto governamental das catástrofes envolve uma grande gama de atuações, que podem ser divididas em: planejamento, execução e informação. As primeiras reúnem os planos de prevenção, contingência, resposta de emergência e redução de vulnerabilidades. Eles deverão ser executados pela defesa civil dos entes federativos e englobam, dentre outras medidas: investimento em sistemas de alerta e monitoramento, identificação e mapeamento das áreas de risco, fiscalização e proteção de áreas verdes e vulneráveis, replanejamento das cidades a partir dos aprendizados impostos por desastres anteriores (resiliência), definição e execução eficiente de políticas públicas de habitação aptas a mitigar as causas mais comuns das catástrofes etc. $A$ atuação do Poder Executivo (municipal, estadual e federal) no que tange à informação e capacitação dos moradores $^{7}$ de áreas impróprias tem o condão de desenvolver o lado da percepção do risco, que é crucial para que o poder público possa fortalecer suas redes de atuação.

Nesse âmbito, é pertinente a descrição de Canotilho (1995, p. 3035) acerca da delimitação positiva do Estado Democrático Ambiental. Na sua dimensão positiva, o Estado Democrático Ambiental é descrito pelo

\footnotetext{
Merece destaque o projeto que vem sendo desenvolvido desde maio deste ano, com o apoio de coordenadorias estaduais e municipais de Defesa Civil, em 5 (cinco) estados brasileiros. O projeto tem como enfoque principal o treinamento específico das comunidades em áreas de risco para lidar com desastres naturais. As atividades são desenvolvidas através de um Simulado de Preparação para Desastres (SPD). No dia 12 de novembro, foi a vez de Novo Hamburgo (RS). Maceió (AL), Recife (PE), Salvador (BA), Petrópolis (RJ) e Nova Friburgo (RJ) também já participaram. Segundo o secretário nacional de Defesa Civil, Humberto Viana, "o simulado serve não só para que os moradores de comunidades em áreas de risco saibam o que fazer em caso de desastres, como também capacitá-los para atuar de forma preventiva, consolidando procedimentos permanentes de monitoramento, alerta e alarme". As cidades foram elencadas a partir de registros históricos de eventos climáticos extremos responsáveis por maiores prejuízos, óbitos e transtornos. A partir do ano que vem, além da repetição dessas mesmas cidades, há a previsão de ampliação dos simulados, que passarão a ser regulares em outras regiões do país. Rodrigues, Alex. Agência Brasil. Comunidades em áreas de risco de cinco estados participarão de simulados de preparação para desastres. Disponível em: http://agenciabrasil.ebc.com.br/ noticia/2011-11-03/comunidades-em-areas-de-risco-de-cinco-estados-participarao-de-simulados-depreparacao-para-desastres. Acesso em: 04 nov. 2011.
} 
autor lusitano como um Estado "aberto", no qual os cidadãos têm o direito de obter dos poderes públicos informações sobre situações ambientais que Ihes sejam relevantes ou desejadas (direito de informação sobre o "estado do ambiente") ${ }^{8}$. A política do ambiente tem um suporte social generalizado e é dinamizada por iniciativas dos cidadãos, possibilitando a formação de um compromisso ambiental da sociedade civil no "Estado Democrático do Ambiente". Este impõe uma dimensão participativa que valoriza e até estabelece como "dever" a participação dos cidadãos nos procedimentos administrativos ambientais. Nesse âmbito, as associações de proteção ao meio ambiente adquirem uma posição de destaque como instrumento de democracia direta (formação de grupos de pressão, legitimidade processual, fomentadores de informações e propostas ambientais, polícias do ambiente etc.). $\mathrm{O}$ Estado Democrático Ambiental tem por objetivo a formação de um "Estado de Justiça Ambiental", proibindo-se iniquidade e qualquer espécie de discriminação ambiental tida através de quaisquer decisões, seleções, práticas administrativas ou ações materiais que digam respeito à tutela ambiental ou à transformação do território e que onerem de forma injusta determinados grupos, comunidades, minorias e indivíduos em vista de sua raça, situação econômica ou localização geográfica.

Sob essa perspectiva, cabe ao Estado de Direito Ambiental investir na redução da conhecida relação entre catástrofe e vulnerabilidade, que geralmente assola os grupos menos favorecidos economicamente e as sociedades (cidades) menos preparadas estruturalmente. Um país ou uma localidade sofre maior ou menor impacto de um desastre, dependendo da forma como se preparou para enfrentá-lo. Exatamente sob esse aspecto aparece a necessidade de uma estrutura organizada e eficiente. Essa estruturação requer uma rede integrada de atuações, que comportem medidas do Executivo, do Legislativo e, quando for o caso, do Judiciário.

Acerca do direito à informação e o meio ambiente, ver Machado (2006). Como sabiamente coloca o autor, "ao contrário do que parece, as autoridades públicas não são proprietárias das informações relativas ao meio ambiente, mas apenas gestoras desses dados em nome da coletividade, sendo que todos têm direito ao esclarecimento, ainda que não o solicite". 
Sob o ponto de vista político-administrativo, o Brasil conta com um plano da Defesa Civil, atualmente complementado pela recente legislação sobre o tema, conforme será vislumbrado a seguir. Entretanto, nada foi capaz de deter um número considerável de catástrofes em vários estados brasileiros, especialmente nos últimos 5 anos. Uma das explicações para tanto é a reconhecida falta de investimento em prevenção. Desastres sofrem do "mal da mídia". Quando acontecem, são incessantemente noticiados e medidas são anunciadas para aplacar o pânico da população. Contudo, logo em seguida, as medidas perdem fôlego na mesma proporção em que a mídia se desinteressa pelo assunto. O Estado de Direito Ambiental das catástrofes tem a difícil missão de ultrapassar essa praxe. Nesse âmbito, a atuação do cidadão como fiscalizador da atividade executiva e parlamentar é de grande relevância e responsabilidade. Para tanto, a compreensão da estrutura e da forma com que, aos poucos, a regulamentação legislativa das catástrofes vem se materializando no país é o primeiro passo. Tratase de uma institucionalização que tem reflexos na política e no direito, isto é, no Estado de Direito sensível às questões ambientais, portanto, Ambiental. É o que se verá no item a seguir.

\section{A estruturação normativa das catástrofes no Brasil}

Atualmente, sob o ponto de vista da legislação ordinária, as leis $12.340 / 2010$ e 12.608/2012 aglutinam a previsão normativa sobre os desastres no Brasil.

A Lei 12.340/2010 dispõe sobre as transferências de recursos da União aos órgãos e entidades dos estados, municípios e Distrito Federal para a execução de ações de resposta e recuperação das áreas atingidas por desastre, e sobre o Fundo Especial para Calamidades Públicas ${ }^{9}$.

\footnotetext{
9 Redação alterada pela Lei 12.608/2012.
} 
A Lei 12.608/2012 institui a Política Nacional de Proteção e Defesa Civil (PNPDEC); dispõe sobre o Sistema Nacional de Proteção e Defesa Civil (SINPDEC) e o Conselho Nacional de Proteção e Defesa Civil (CONPDEC); autoriza a criação de sistema de informações e monitoramento de desastres; altera as leis 12.340 , de $1^{\circ}$ de dezembro de 2010, 10.257, de 10 de julho de 2001, 6.766, de 19 de dezembro de 1979, 8.239, de 4 de outubro de 1991, e 9.394, de 20 de dezembro de 1996; e dá outras providências.

Dentre as inovações de planejamento e organização trazidas pela legislação com vistas à redução de ocorrência dos desastres, está a institucionalização da obrigatoriedade de mapeamento das áreas de risco nos territórios dos estados e Distrito Federal. Aos municípios cadastrados, competirá o cumprimento de uma série de obrigações, quais sejam: elaboração de plano de contingência e instalação de núcleos de Defesa Civil, mapeamento de áreas de risco, criação de mecanismos para evitar a edificação em locais propícios a escorregamentos, e a elaboração de carta geotécnica com diretrizes voltadas à segurança de novos parcelamentos do solo urbano.

A atuação dos municípios vinculados ao sistema é bem definida. Assim, identificadas as áreas de risco, o ente federativo deverá adotar medidas para a sua redução, dentre as quais: a execução de obra de contingência ou de segurança e, quando necessário, a remoção das edificações e o reassentamento dos seus ocupantes em lugar seguro. A possibilidade de remoção de edificações, ao mesmo tempo em que concede ao município certa autonomia, só se torna possível se atendidos os requisitos legais. Nessa senda, primeiro, é preciso que o município providencie um laudo técnico demonstrando que a ocupação daquela área apresenta riscos à integridade física dos ocupantes. Em um segundo momento, de posse desse laudo, o poder público deverá notificar as pessoas e informá-las sobre as alternativas de abrigo oferecidas pelo poder público, como garantia do direito à moradia. $A$ 
alternativa da lei para esses casos é que as pessoas removidas das áreas de risco sejam inscritas em programas habitacionais do governo ${ }^{10}$.

Sob a perspectiva financeira, o apoio do Poder Executivo Federal em situações de desastres é complementar aos estados e municípios atingidos (inclusive Distrito Federal). Esse apoio dependerá do reconhecimento dos seguintes critérios: situação de emergência ou estado de calamidade pública (condição de possibilidade para a liberação de recursos). A declaração deve ser solicitada pelo ente afetado por qualquer uma das situações ${ }^{11}$.

Ainda no que concerne aos recursos financeiros, a lei dá nova redação ao Fundo Especial para Calamidades Públicas (FUNCAP), revogando o decreto de 1969 que o estabeleceu. O Fundo é um instrumento financeiro, previsto para o atendimento emergencial em ações de resposta às catástrofes, e seu patrimônio será constituído pela integralização de cotas anuais e voluntárias dos entes federativos, na proporção de 3 (União) para 1 de cada ente federado. A retirada dessas cotas pelos entes federados somente será possível após o prazo de 2 anos, com exceção de duas situações: ocorrência de desastre nesse período ou custeio de ações imediatas de socorro, assistência às vítimas e restabelecimento de serviços essenciais em áreas afetadas ${ }^{12}$.

Interessante destacar que no momento da edição da Lei $12.340 / 2010$ os auxílios financeiros estavam voltados prioritariamente à fase de recuperação ou pós-desastre. Essa perspectiva muda notoriamente com a edição da Lei 12.608/2012. Nela, a precaução vem duplamente qualificada pelo legislador. Em um primeiro momento, é posta como dever dos entes da Federação, entidades públicas, privadas e da

\footnotetext{
10 Art. $3^{\circ}$ - B. Verificada a existência de ocupações em áreas suscetíveis à ocorrência de deslizamentos de grande impacto, inundações bruscas ou processos geológicos ou hidrológicos correlatos, o município adotará as providências para redução do risco, dentre as quais, a execução de plano de contingência e de obras de segurança e, quando necessário, a remoção de edificações e o reassentamento dos ocupantes em local seguro. (Incluído pela Lei n 12.608 , de 2012).

11 Artigo $3^{\circ}$, $\S \S 1^{\circ}$ e $2^{\circ}$ da Lei $12.340 / 2010$.

12 Artigo $9^{\circ}$, $\S 4^{\circ}$ e artigo 13 da Lei 12.340/2010.
} 
sociedade em geral. Em um segundo momento, suplanta as alegações e justificativas de má ação ou omissão em função da dificuldade concreta (científica) de definição quanto à magnitude/probabilidade de um evento potencialmente desastroso. Significa dizer que incerteza quanto ao risco de desastre não é razão para a não ação ${ }^{13}$. Pelo contrário, pois muitos casos de desastres apresentam baixa probabilidade e alta magnitude de impacto.

Em complemento à recente previsão legislativa, o Poder Executivo instituiu o cartão de pagamento da Defesa Civil. A medida, adotada pelo governo federal e regulamentada através do Decreto $7.505 / 2011$, objetiva fortalecer a gestão pública interfederativa, fomentar o controle governamental e social, além de promover a transparência do gasto público por meio da divulgação dos pagamentos realizados com o novo instrumento. A ideia é evitar malversação, desvios ou utilização dos recursos transferidos. Regulamentado pelo Decreto $\mathrm{n}^{\circ}$ $7.257 / 2010$, o cartão de pagamento da Defesa Civil é destinado ao pagamento de despesas com ações de socorro, assistência às vítimas e restabelecimento de serviços essenciais, devendo ser usado por governos estaduais, municipais e do Distrito Federal exclusivamente em situações de emergência ou de calamidade pública, reconhecidas pela Secretaria Nacional de Defesa Civil.

Outro exemplo de atuação prática governamental de grande relevância - neste caso, com foco maior na prevenção - foi a criação do Centro de Monitoramento e Alertas de Desastres Naturais (CEMADEM). O Centro tem por objetivo desenvolver, testar e implementar um sistema de previsão de ocorrência de desastres naturais em áreas suscetíveis de todo o Brasil. Sua atuação compreenderá também a identificação de vulnerabilidades no uso e ocupação do solo, com destaque para o planejamento urbano e a instalação de infraestruturas. Atuará, ainda, no aumento da consciência e prontidão da população em risco, induzindo

13 Artigo $2^{\circ}, \S 2^{\circ}$ da lei $12.608 / 12$. 
ações efetivas e antecipadas de prevenção e redução de riscos de desastres. Em linhas gerais, o objetivo é elevar o Brasil a um novo patamar na capacidade de antecipar-se a desastres naturais causados por eventos extremos do tempo. O monitoramento bem aparelhado das observações da atmosfera, superfície e sensoriamento remoto é um subsídio fundamental para uma atuação eficaz da Defesa Civil em termos de alerta e prevenção. Criado em 2011, o CEMADEM foi regulamentado pelo Decreto 7.513/2011, fonte legislativa que dispõe também acerca das contratações de pessoal para a estruturação dos recursos humanos especializados nas áreas afins à gestão preventiva dos riscos de catástrofes. O centro encontra-se em funcionamento no município de Cachoeira Paulista-SP.

Todo esse processo de sensibilização legislativa e governamental à necessidade de prevenção e mitigação da evolução das causas de catástrofes no paísé de indiscutível relevância. Emque peseanecessidade de aprimoramento, a Lei 12.608/2012 possui, predominantemente, aspectos positivos, especialmente se comparada à sua antecessora. Seu ponto alto é a assimilação do que se pode denominar de "círculo de gestão do risco" (FARBER, 2012). Esse círculo é composto pelas seguintes estratégias ou elementos: mitigação, resposta de emergência, reconstrução e compensação, os quais deverão permear a prática do direito, da política e das atuações governamentais, de forma constante, circular, preventiva e comprometida.

\section{Conclusão}

A institucionalização das catástrofes ambientais tanto na agenda de governo quanto dos cidadãos já é uma realidade no Brasil. A partir dessa constatação, pretendeu-se alocar as catástrofes ambientais como uma temática altamente complexa, que precisa ser racionalizada pelos sistemas sociais, destacando-se, neste trabalho, o direito e a política. Acredita-se que, ao mesmo tempo em que demanda uma estrutura própria, essa racionalização requer uma atuação integrada. 
A observação das ressonâncias das catástrofes ambientais nos sistemas sociais, especialmente no direito e na política, foi feita com a lente do Estado de Direito Ambiental. Importante salientar que este aparece como ressonância (do direito e da política aos desastres) e também como estratégia de reação, principalmente por sua essência, às catástrofes ambientais. Não se quis, com isso, defender que ao Estado (enfraquecido, como se sabe) cabe o papel de protagonista único. Nessa longa caminhada, e em apoio ao Estado, o cidadão, os Ministérios Públicos, os órgãos públicos fiscalizadores e as entidades não governamentais precisam assumir uma posição proativa

No contexto social de necessária redução das complexidades geradas por uma catástrofe, é necessário pensar o papel da política e do direito a partir de uma perspectiva preventiva, estruturada, integradora e sustentável. Desastres ambientais comunicam a necessidade de uma atuação sistêmica, coordenada e precavida do Estado e dos diversos sistemas sociais envolvidos (direito, economia, política etc.).

Nesse propósito, após discorrer sobre a lógica evolutiva da noção de Estado de Direito até a qualificação de Estado de Direito Ambiental, pretendeu-se problematizar de que forma as ações da política (Legislativo) e do governo vêm assimilando as catástrofes. Sem a pretensão de afirmações conclusivas, o que seria precipitado, dada a incipiência da matéria, pode-se dizer que, hoje, o Brasil conta com uma estrutura legislativa de prevenção e recuperação. Entretanto, organizacionalmente, a realidade está mais voltada à recuperação ou reconstrução pós-catástrofes. Trata-se de uma atuação que acontece depois do evento, o que é, na maioria das vezes, muito dispendiosa e paliativa. Isso se deve à conhecida falta de investimento em prevenção, que, aos poucos, parece se desenvolver, especialmente diante dos recorrentes anúncios de liberação de recursos para tal. Por enquanto, é fato que a falta de preparação e planejamento de longo prazo têm sido as principais características das políticas públicas relacionadas aos desastres no país.

Essa realidade tem seus reflexos também em termos legislativos, uma vez que a Lei 12.340/10, inicialmente, mostrou-se muito mais 
preocupada com a reconstrução e financiamento pós-catástrofe. A revogação de alguns de seus artigos e a nova redação da Lei 12.608/12 demonstra que o legislador começa a compreender que catástrofe ambiental e seus elementos potencializadores são combatidos com investimento e estrutura em prevenção.

Desastres significam irreversibilidades de vidas e ecossistemas e representam, dependendo de sua gravidade, a impossibilidade para as futuras gerações de fruição de um bem (ambiental) que é de uso comum. Daí a relevância da inserção da gestão do risco em todas as fases de um desastre, como programa de decisão a ser posto em prática pelo direito e pela política. Os desastres ambientais conjugam uma relação de presente, passado e futuro muito valiosa. A antecipação a um desastre com consequências catastróficas e irreversíveis depende, na maioria dos casos, do aprendizado com os erros do passado e da abertura, no presente, às incertezas e improbabilidades sinalizadas para o futuro. Nessa perspectiva, o desafio é maior para o direito do que para a política, pois aquele apresenta, tradicionalmente, grande dificuldade de abertura à noção de futuro.

As novas questões ecológicas, dentre elas, os desastres, entram cada vez mais em rota de colisão com a tradicional estrutura normativa do direito, arraigada à noção da certeza e do passado. Em viés totalmente oposto a essas concepções, os desastres, fenômenos multicomplexos, requerem uma resposta do direito e da política que permita a assimilação dos riscos sob uma perpectiva preventiva. Esse deve ser o propósito basilar das atuações que seguramente representam o início de uma racionalização estrutural anticatástrofes no Brasil.

\section{Referências}

BECK, U. Risk society: towards a new modernity. London: Sage, 1992. BOBBIO, N. A era dos direitos. Rio de Janeiro: Campus, 1992.

BRASIL. Decreto n. 7513, de $1^{\circ}$ de julho de 2011. Disponível em: <http://www.planalto.gov.br/CCIVIL_03/_Ato2011-2014/2011/Decreto/ D7513.htm>. Acesso em: 20 out. 2011. 
BRASIL. Lei 12.340, $1^{\circ}$ de dezembro de 2010. Disponível em: <http:// www.planalto.gov.br/ccivil_03/_ato2007-2010/2010/Lei/L12340.htm>. Acesso em: 10 dez. 2010.

CAMERON, J. Globalization and the ecological state. Review of European Community and International Environmental Law, London, v. 8, n. 3, p. 243-250,1999.

CANOTILHO, J. J. G. Brancosos e interconstitucionalidade: itinerários dos discursos sobre a historicidade constitucional. Coimbra: Almedina, 2006.

CANOTILHO, J. J. G. Estado constitucional ecológico e democracia sustentada. In: GRAU, E. R. Estudos de direito constitucional: em homenagem a José Afonso da Silva. São Paulo: Malheiros, 2003. p.101110.

CANOTILHO, J. J. G. Estudos sobre direitos fundamentais. Coimbra: Ed. Coimbra, 2004.

CANOTILHO, J. J. G. Juridicização da ecologia ou ecologização do direito. Revista Jurídica do Urbanismo e do Ambiente, Coimbra, n. 4, p. 69-79, 1995.

CRUZ P. M.; ZENILDO, B. O novo paradigma do direito na pósmodernidade. Revista de Estudos Constitucionais, Hermenêutica e Teoria do Direito, São Leopoldo, v. 3, n. 1, p. 75-83, jan./jun. 2011.

DAVID, R. Os grandes sistemas do direito contemporâneo. São Paulo: Martins Fontes, 2002.

DE GIORGI, R. Direito, democracia e risco: vínculos com o futuro. Porto Alegre: Fabris, 1993.

DIAMOND, J. Colapso: como as sociedades escolhem o fracasso ou o sucesso. São Paulo: Record, 2010.

FARBER, D. Disaster law and emerging issues in Brazil. Revista de Estudos Constitucionais, Hermenêutica e Teoria do Direito, v. 4, n. 1, p. 2-15, jan./jun. 2012. 
FARBER, D. et al. Disaster, law and policy. New York: Aspen Publishers, 2010.

FERRER, G. R. La construcción del Derecho Ambiental. Revista Arazandi de Derecho Ambiental, Pamplona, v. 1, n.1, p. 1-29, 2002.

KELSEN, H. Teoria pura do direito. São Paulo: Martins Fontes, 2006.

LEITE, J. R. M.; FERREIRA, H. S. (Org.). Estado de direito ambiental: tendências. Rio de Janeiro: Forense Universitária, 2004.

LUHMANN, N. Sistemas sociales: lineamentos para una teoria general. México: Alianza Editorial/Universidad Iberoamericana, 1991.

LUHMANN, N. Teoría política en el estado de bienestar. Madrid: Alianza Universidad, 1997.

MACHADO, P. A. L. El derecho de la sociedad. México: Universidad Iberoamericana, 2002.

. Direito à informação e meio ambiente. São Paulo: Malheiros,

2006.

QUARANTELLI, E. L. et al. The caracteristics of catastrophes and their social evolituion: an exploratory analysis of implications for crisis policies and emergency management procedures. Disaster Research Center, Newark, v. 90, p.1-33, 2008.

RANGEL, Paulo Castro. Concertação, programação e direito do ambiente. Coimbra: Ed. Coimbra, 1994.

REZEK, J. F. Direito internacional público: curso elementar. São Paulo: Saraiva, 1995.

ROCHA, L. S. Epistemologia jurídica e democracia. São Leopoldo: Unisinos, 2003.

ROMESÍN, H. M.; GARCÍA, F. J. V. A árvore do conhecimento: as bases biológicas da compreensão humana. São Paulo: Palas Athena, 2001.

- De máquinas e seres vivos: autopoiese: a organização do vivo. Porto Alegre: Artes Médicas, 1997. 
SILVA, J. A. Fundamentos constitucionais da proteção do meio ambiente. Revista de Direito Ambiental, São Paulo, v. 27, p. 51-57, 2002.

SILVA, V. P. Verdes são também os direitos do homem: responsabilidade administrativa em matéria de ambiente. Cascais: Principia, 2000.

VERCHICK, R. R. M. Facing catastrophe: environmental action postKatrina world. Cambridge: Harvard University Press, 2010.

Recebido em: 07/03/12

Aprovado em: 04/05/12 